Ensino

\title{
"A Química é uma área experimental!": discursos sobre a experimentação em um curso de formação de professores de Química
}

\author{
"Chemistry an experimental area!": discourses about experimentation \\ in a chemistry teacher training course
}

\author{
Edson Frozza 1(i), Bruno dos Santos Pastoriza'(i) \\ 'Universidade Federal de Pelotas, Pelotas, RS, Brasil
}

\section{RESUMO}

Este estudo teve por objetivo compreender a circulação de discursos que mobilizam uma concepção sobre a relação entre a Química e a experimentação em um curso de Licenciatura em Química, assumindo sua função de orientador de práticas e buscando problematizar seus efeitos na formação de professores e na Educação Básica. Foram empregadas bases teóricas e metodológicas da Análise do Discurso no processo de pesquisa, análise e construção do texto. A análise aponta a emergência de discursos que se pautam numa concepção de que a Química é uma área essencialmente experimental e que produz e reproduz práticas, seja na produção do conhecimento químico, seja nos processos de ensino e aprendizagem, que têm como base fundamental a realização de experimentos. Em relação ao ensino, essa concepção perpassa ideias que merecem mais problematizações, como a de que o experimento por si já é suficiente para a aprendizagem e de que a Química se aprende fazendo. Os resultados apresentados neste trabalho evidenciam a importância em se repensar práticas que são naturalizadas nos cursos de formação de professores de Química.

Palavras-chave: Formação de professores; Experimento; Ensino de química

\begin{abstract}
This study aimed to understand circulation of discourses that mobilize a conception about the relationship between Chemistry and experimentation in a Chemistry Degree course, assuming its role as a supervisor of practices and seeking to problematize its effects on teacher education and Basic Education. Theoretical and methodological bases of Discourse Analysis were used in the process of research, analysis and construction of the text. The analysis points to emergence of discourses based on a conception that Chemistry is essentially an experimental area and that produces and reproduces practices, whether in production of chemical knowledge, or in teaching and learning processes, which
\end{abstract}


are fundamentally based on achievement of experiments. In relation to teaching, this conception runs through ideas which are possible to problematize, such as that of experiment itself is enough for learning and that Chemistry is learned by doing. The results presented in this work show the importance of rethinking practices that are naturalized in the chemistry teacher training courses.

Keywords: Teacher education; Experiment; Chemistry teaching

\section{INTRODUÇÃO}

A área da Química geralmente está associada à experimentação e à realização de experimentos, sejam eles no desenvolvimento de pesquisas inovadoras que buscam superar o conhecimento já existente, sejam para ratificação, comprovação, demonstração de conhecimentos validados. Essa relação entre os conhecimentos químicos e a experimentação também é evidenciada no campo do ensino da Química (SILVA et al., 2012; QUADROS et al., 2011; GONÇALVES, 2009; TOMAZI et al., 2009; MESQUITA; SOARES, 2008). Seria a Química uma área do conhecimento essencialmente experimental? Como essa relação aparece em programas de formação de professores de Química? A partir desses questionamentos, desenvolvemos, neste estudo, uma pesquisa junto a professores do ensino superior, propondo algumas discussões com o fim de entender que discurso sobre essa relação Química/Experimento está presente na formação de professores de Química e de que modo eles orientam as práticas docentes.

A pesquisa foi realizada com um grupo de professores que ministram aulas em disciplinas experimentais no curso de Licenciatura em Química da Universidade Federal de Pelotas (UFPel), além da análise do Projeto Pedagógico do Curso de Licenciatura em Química (PPC) e um grupo disperso de textos produzidos no campo da Educação e da Educação Química. Utilizamos como referencial teórico-metodológico a Análise de Discurso tendo como base as compreensões de Michel Foucault (2016), sendo empreendido o trabalho de tematização de documentos (MARÍN-DÍAZ, 2009; PASTORIZA; DEL PINO, 2017). A Análise de Discurso e a organização dos ditos sobre experimentação que circulam no Ensino Superior, neste caso especificamente no curso de formação de professores de Química, nos permitem identificar algumas temáticas 
em que há uma intensa ação do discurso. Uma dessas temáticas, que abordaremos neste texto, é justamente o modo como é compreendida essa relação entre conhecimentos químicos e experimentos, o que implica em um modo de compreender a própria Química.

A análise das falas dos professores e dos documentos mostrou que há um discurso que caracteriza a Química como uma aula experimental e que este discurso também está presente nos cursos de formação de professores de Química. O modo como o curso está organizado assim como as práticas docentes produzem e reproduzem situações que reforçam o experimento como base na produção do conhecimento químico. Nas seções seguintes discutimos acerca de alguns elementos que embasam nossa proposição.

\section{EXPERIMENTO COMO BASE NA PRODUÇÃO DO CONHECIMENTO CIENTÍFICO}

As abordagens que a área da Química apresenta em relação à produção dos seus conhecimentos, assim como no processo de ensino e de aprendizagem, produzem e reproduzem um discurso que coloca em evidência, durante esses processos, a experimentação. Os experimentos estão, geralmente, diretamente ligados aos desenvolvimentos que ocorre no campo científico da Química. Alguns estudos apontam haver uma naturalização dessa relação intrínseca entre Química e experimentação, seja na pesquisa com viés no desenvolvimento conceitual e tecnológico da Química, seja na área da Educação, que resultam por constituir um campo científico essencialmente experimental (GONÇALVES, 2009; TOMAZI et al. 2009; LENOIR, 2004; LATOUR; WOOLGAR, 1997).

As ideias de que a produção dos conhecimentos na área das Ciências se dá essencialmente em laboratórios e, principalmente, por meio da realização de experimentos foram questões de estudos de pesquisadores como Latour e Woolgar (1997), que investigaram como o conhecimento é produzido em um laboratório, e 
Lenoir (2004), que propôs uma discussão acerca da constituição de uma disciplina científica. Para Lenoir (2004, p. 40):

o objetivo da experimentação é criar fenômenos puros isolados, de uma forma confiável e repetível, usando a aparelhagem e as técnicas tornadas disponíveis por nossa cultura técnica corrente. Fenômenos como o efeito Hall, o efeito Josephson, o efeito Faraday, inclusive lasers e masers, argumenta Hacking, não existem fora da aparelhagem e dos arranjos do laboratório. O que existe na natureza é a complexidade. Nós analisamos essa complexidade produzindo nesse laboratório fenômenos puros, isolados. O contexto prático do laboratório e da cultura da vida de laboratório é, dessa forma, essencial à produção de conhecimento.

A experimentação, apontada na análise do autor como base para a produção do conhecimento nas Ciências, se utiliza de equipamentos sofisticados para produzir e reproduzir experimentos que se diferem dos fenômenos naturais. Isso, de certo modo, produz uma compreensão de que os conhecimentos químicos, produzidos em laboratório, estão distantes do que acontece na sociedade, e por isso, esses conhecimentos são isentos, neutros. Embora, tanto Lenoir (2004) quanto Latour e Woolgar (1997), coloquem em discussão a visão de que a Ciência tem sua base construída na experimentação, o que dá um caráter experimental à área, eles também defendem e trazem elementos que dão à área aspectos que vão além de questões inerentes ao laboratório, que colocam em ação questões sociais, políticas, econômicas e técnicas. Eles colocam em xeque a ideia de que as disciplinas que constituem a área das Ciências são construídas de forma isolada, isenta de juízo de valores, em um laboratório. Ao descreverem os processos de constituição de uma área de conhecimento apresentam elementos que mostram uma área do conhecimento sendo constituída, modificada, reproduzida dentro de uma formação discursiva, e, portanto, sofre os efeitos de um discurso que não se limita ao espaço do laboratório, mas que se dispersa, que produz e sofre os efeitos de questões sociais, éticas, econômicas, etc.

O entendimento de que os experimentos são a base para a produção dos conhecimentos químicos também estão dispersos no campo da Educação. A ideia de uma Química ligada à realização de experimentos, à realização de um método científico, 
também está presente em livros didáticos de Ensino Superior. Por exemplo, Atkins e Jones (2012, p. F2), já no início do livro, na seção "Como se faz a ciência”, dizem que "os cientistas perseguem ideias por um caminho mal definido, mas eficiente, chamado frequentemente de método científico", e que esse método é desenvolvido em uma sequência de etapas, sendo que, "o primeiro passo é, com frequência, a coleta de dados a partir de observações e medidas. Essas medidas geralmente são realizadas em amostras pequenas, representativas do material que queremos estudar". Nesse sentido, é possível afirmar que uma das etapas do método científico é a realização de experimentos. A tentativa de socialização de determinados conceitos químicos nas mídias, especialmente as televisivas, também reproduzem a descoberta científica associada à laboratórios e a realização de experimentos (TOMAZI; PEREIRA, et al., 2009; MESQUITA; SOARES, 2008).

Seguindo a mesma lógica, de colocar a Química como uma área que depende da experimentação, Giordan (1999, p. 44) diz que:

A elaboração do conhecimento científico apresenta-se dependente de uma abordagem experimental, não tanto pelos temas de seu objeto de estudo, os fenômenos naturais, mas fundamentalmente porque a organização desse conhecimento ocorre preferencialmente nos entremeios da investigação.

No entanto, embora essa percepção esteja difundida no campo da Educação Química, autores como Gonçalves (2009) e Tomazi et al. (2009), por exemplo, criticam um ensino de Química centrado essencialmente em um modelo empirista, que tem como base da produção dos conhecimentos a observação e a realização de experimentos. Para os autores, um ensino da Química fundamentado essencialmente pela experimentação, desconsiderando o papel das teorias no processo de desenvolvimento da área, pode difundir uma ideia de que é apenas por meio das atividades experimentais que os conhecimentos científicos são produzidos.

As críticas são direcionadas ao modelo que centraliza o processo ensino e de aprendizagem na experimentação, na compreensão de que o experimento por si já é suficiente para que o aluno aprenda os conceitos. Outras propostas buscam articular 
a atividade experimental a outros elementos considerados essenciais. Johnstone (1982), por exemplo, propõe que o ensino e a aprendizagem são potencializados na articulação dos três níveis de compreensão da Química, o macroscópico, o submicroscópico e o simbólico. No mesmo sentido, Mortimer, Machado e Romanelli (2000) propõem os conceitos de fenomenológico, conceitual e representacional. O experimento possibilita a observação dos efeitos fenômenos macroscópicos da Química. Embora o experimento não seja utilizado de modo isolado, ele continua sendo essencial no entendimento e na aprendizagem dos conceitos químicos.

Os elementos apresentados até aqui indicam haver uma concepção já difundida de que o experimento é a base na produção do conhecimento químico, assim como nos processos de ensino e de aprendizagem. Nesse sentido, na sequência do texto, buscamos entender, a partir do discurso disperso em um curso de Licenciatura em Química, se esta concepção também circula na formação de professores e possíveis efeitos que ela produz.

\section{CAMINHOS METODOLÓGICOS DA PESQUISA}

Como o nosso interesse neste estudo está direcionado ao discurso presente nos cursos de formação de professores de Química, optamos por utilizar como aporte teórico metodológico elementos da Análise de Discurso a partir das compreensões de Michel Foucault $(2016,2014)$ e outros autores (PASTORIZA; DEL PINO, 2017; MARINDIAZ, 2009). As noções de discurso que orientam esta pesquisa podem ser organizadas em um grupo de conceituações depreendidas dos estudos de Foucault $(2016,2014)$ como: i) a necessidade de entender o discurso como prática, pois o discurso produz efeitos nas ações sociais ao mesmo tempo em que é produzido, modificado, excluído pelas ações sociais; ii) a atribuição de uma temporalidade ao discurso, já que ele produz e é produto de uma prática desenvolvida no nível social que corresponde a uma determinada época, relações, conjunturas temporalmente localizadas; iii) o nível da dispersão de acontecimentos própria ao discurso, uma vez que o discurso não é algo 
que se possa encontrar numa unidade, pelo contrário, ele só pode ser compreendido num conjunto de acontecimentos dispersos que se relacionam e que seguem certas regras de formação e; iv) a evidenciação da relação intrínseca entre o discurso e o enunciado, porque o discurso, nessa perspectiva, é posto como um conjunto de elementos que se apoiam em um mesmo sistema de formação, num mesmo conjunto restrito e raro de enunciados.

A produção de dados para a análise se deu a partir de três grupos de materiais: (i) uma entrevista semiestruturada com professores das disciplinas experimentais no curso de Licenciatura em Química da Universidade Federal de Pelotas, (ii) as três últimas versões do Projeto Pedagógico do Curso (PPC) e (iii) um conjunto de documentos diversos.

O primeiro foi composto por entrevistas com professores que ministraram disciplinas experimentais no curso de Licenciatura em Química na Universidade Federal de Pelotas (UFPel) nos últimos dois anos. Esses professores são responsáveis pela organização e desenvolvimento das aulas ditas "experimentais" no curso de formação de professores de Química. A escolha deste grupo de professores se deu a partir da compreensão de que o sujeito é uma função subjetiva, a qual "é uma função vazia, podendo ser exercida por indivíduos, até certo ponto, indiferentes, quando chegam a formular o enunciado" (FOUCAULT, 2016, p. 113). Sendo assim, o que é preciso analisar não é a relação entre o sujeito e o que ele disse, mas a posição que esse sujeito ocupa em determinado enunciado. Assumir a posição docente como uma função subjetiva possibilita trabalhar seus ditos e posições a partir da noção de produção do discurso. Assim, o discurso analisado não pertence ao professor, indivíduo, mas à função subjetiva professor. Participaram das entrevistas oito professores que foram identificados no decorrer da análise por P1, P2...P8. Todos eles receberam e assinaram o termo de consentimento livre e esclarecido.

O segundo grupo é formado pelas três últimas versões do Projeto Pedagógico do Curso (UFPel, 2016, 2013, 2009). Esses documentos orientam a organização dos cursos de formação de professores de Química, por isso, além de serem produzidos 
dentro de discursos que legitimam as ações e a organização dos cursos, também reproduzem discursos já consolidados articulando diferentes níveis da ação do discurso, como o discurso legal, o discurso institucional, dentre outros níveis da construção discursiva.

O terceiro grupo de materiais foi constituído por um conjunto de documentos diversos (artigos acadêmicos produzidos no campo da Educação Química, livros didáticos, documentos oficiais, textos jornalísticos, dentre outros). Este grupo permite evidenciar a dispersão do discurso e a evidenciação de um espaço de diferenciação (FOUCAULT, 2016) daquele conjunto de sujeitos, práticas e temporalidades da formação em Química do Ensino Superior. Tais materiais diversos não foram sistematicamente reunidos, mas discursivamente organizados, sendo essas publicações buscadas de modo à tensionar os elementos que foram sendo constituídos nas análises dos dois primeiros conjuntos de materiais.

Os monumentos selecionados para análise foram decompostos em unidades, ou trechos, os quais apresentavam elementos considerados por nós, analistas, importantes e significativos à ação do discurso. Da articulação dessas unidades e de seu tensionamento com o campo de diferenciação, foram constituídas temáticas (PASTORIZA; DEL PINO, 2017; MARIN-DIAZ, 2009), as quais são um modo possível de organizar a dispersão do discurso por meio de uma lógica, coerência ou modo de sua ação. De modo esquemático, a sistematização da análise empreendida sobre tais materiais está apresentada na Figura 1. 
Figura 1- Sistematização do processo de análise

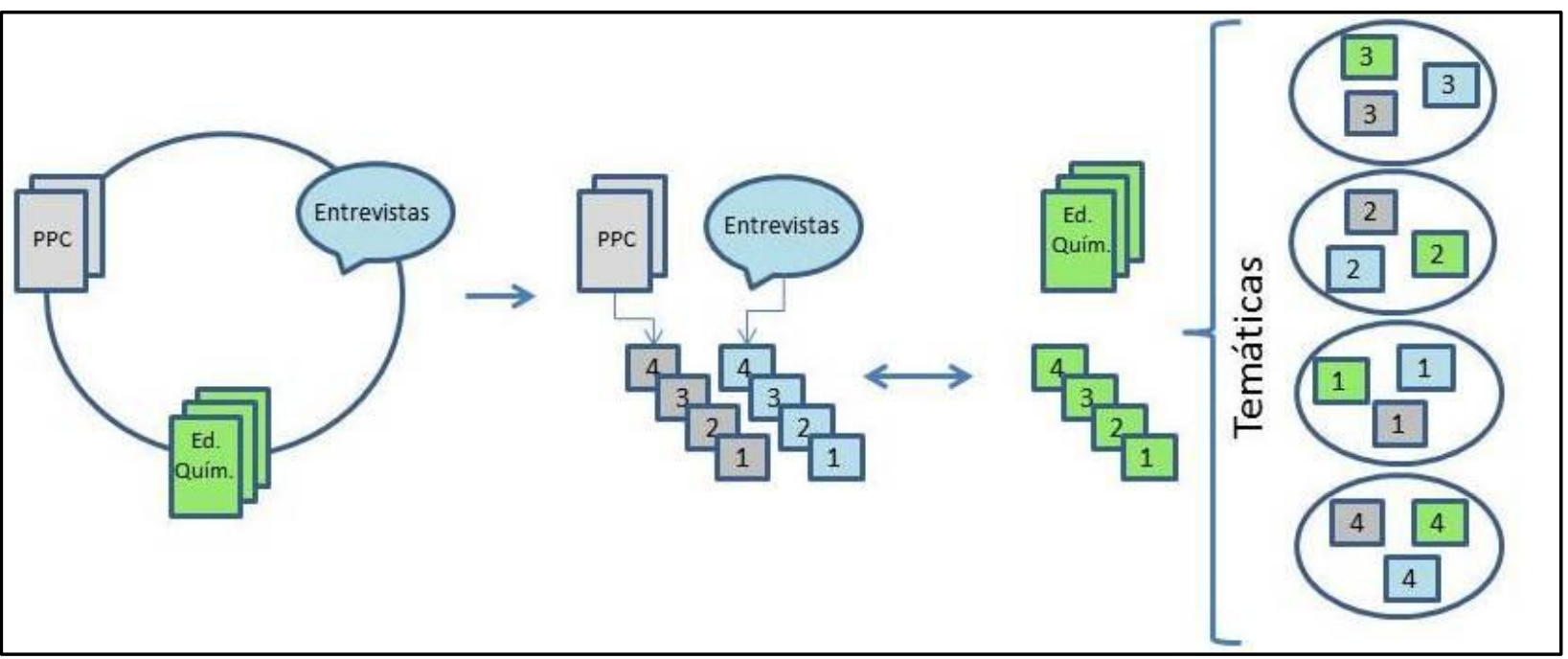

Fonte: Autoria própria, 2021

\section{O EXPERIMENTO E O APRENDER QUÍMICA}

Ao discutir alguns dos pontos que foram sendo evidenciados durante as análises, nas falas dos professores, nos PPCs, assim como no campo da Educação Química, surgiram elementos que nos permitiram delinear um modo de ver a Química no Ensino Superior que a caracteriza como uma área que baseia a produção do conhecimento, fundamentalmente, pela experimentação.

Um primeiro ponto que emerge na fala dos professores e que permite entender o eles pensam em relação à importância da experimentação na Química foi a resposta que deram ao serem questionados sobre a possibilidade de um curso de licenciatura ser desenvolvido sem aulas experimentais. Todos afirmaram não ser possível ou que seria inadequado. Isso significa que para ter uma boa formação na área da Química, mesmo na licenciatura, é preciso ter contato, aprender, experienciar o laboratório e as atividades experimentais. A fala dos professores põe em destaque uma Química que apresenta necessidade da experimentação. Esse modo de pensar acerca da Química também se evidencia em trechos das falas como:

Bom, na minha visão, eu acho que a aula experimental é a aula aonde o aluno vai se descobrir como químico. Claro, na química, porque ele tem a condição de ter um tato, de executar as coisas (P2). 
Eu quero que eles aprendam o porquê das coisas. Porque na química tem muita essa coisa de fazer abordagem na teoria, mas na prática não sabe o porquê das coisas. Eu acho que o grande objetivo da aula experimental é saber o porquê, é descobrir o porquê das coisas (P3).

[Sem] A experimentação não tem como, por que a área da química, embora vocês trabalhem com a licenciatura, tenham uma visão um pouco diferente em relação à parte pedagógica e tudo mais e tal, mas a área de química de um modo geral ela é uma área experimental né. [...] Primeiro veio a prática. A teoria nasceu tudo em função de tentar explicar o que se observava no laboratório. Então na área de química não tem jeito, a experimentação é fundamental, sem ela você não vai ter uma formação sólida, de um bom profissional na área da Química (P5).

O que se evidencia são elementos que indicam a existência de uma Química dependente da experimentação. Falas como a do professor P5, de que primeiro veio a prática e que a teoria veio para explicar o que era observado, marca um argumento histórico, como se pelo fato de, em algum momento ter sido assim, que deva sempre ser assim. São elementos presentes no discurso, de um modo de compreender a Química, que não é questionado.

Também há a compreensão de que é no laboratório que a Química ocorre.

É tentar trazer para o laboratório, tentar trazer aquilo que o aluno só ouviu falar, para ele poder ver. Então, a parte do laboratório é fundamental. Eu acho mais importante até do que a teoria, porque é claro, por ser mais demorado a gente acaba tendo mais tempo, porque muitas reações são bastante demoradas, mas eu acho que é ali que tu vê a química acontecendo (P5).

A função [do laboratório] de ver as coisas, de tocar, de sentir o cheiro e de ver como essas coisas que você só faz no papelzinho, não sabe o que acontece. Se você escreve uma reação isotérmica tu vai saber o que acontece (P7).

Dessa forma, o espaço do laboratório e a realização das atividades experimentais são compreendidos como o local e o momento em que a Química ocorre de fato. Esse modo de pensar sobre a disciplina, aliado à fala do professor P7, de que é apenas na teoria não é possível saber o que realmente acontece nos processos químicos, evidencia outro elemento: o de que ela só é aprendida quando é trabalhada, vista, percebida, por meio da experimentação. Reforça-se a existência de uma Química que 
se faz experimental. Nesse sentido para aprender ou compreender os conceitos, é preciso fazer, tocar, cheirar, desenvolver as atividades na prática. Esse modo de pensar na e sobre a Química, embora não seja problematizado, está dito efetivamente.

A química é algo extremamente palpável, se você, eu acredito que se você não tocar, você não conhecer, você não fazer o experimento, fica muito abstrato. Então na parte da química, eu acredito que não [é possível ter um curso de química sem aula experimental], mesmo na licenciatura ali eu acho que o pessoal tem que ter a parte experimental pra auxiliar na formação do aluno (P2).

Ter contato com a vidraria, entrar no laboratório, usar um EPI, saber como manipular um reagente né, saber pipetar, saber como determinar o menisco, ou mesmo fazer umas reações simples, então isso tudo é importante, mesmo quem vai ministrar só teoria dali por diante (P1).

Fica evidente a compreensão de que na Química é preciso ir para o laboratório fazer as atividades experimentais. Os experimentos, como discutido anteriormente, são vistos como a base da produção dos conhecimentos químicos, por isso, é compreensível que haja o entendimento de que, se tratando de aprender Química, seja necessária a vivência em laboratório. Esse modo de ver a Química não só está presente nos cursos de formação de professores, como produz efeitos no modo como esses futuros professores, quando atuando na Educação Básica, pensam os processos de ensino e de aprendizagem. Silva et al. (2012, p.142) ao desenvolverem pesquisa junto a professores dos anos iniciais da Educação Básica, destacam que estes professores acreditam que:

[...] a atividade experimental possibilita a aprendizagem porque os alunos estarão fixando melhor os conteúdos, por meio da ação física sobre os objetos. Nesse mesmo sentido, alguns docentes acreditam que a atividade experimental auxilia na aprendizagem porque os alunos estarão tocando, mexendo, visualizando os objetos.

Embora no campo da Educação Química ainda seja possível evidenciar um discurso que valoriza o aprender fazendo como um dos elementos fundamentais na aprendizagem, por exemplo, quando há proposição de que é o próprio aluno quem deve desenvolver as atividades experimentais (MORI; CURVELO, 2017), também é possível evidenciar nessa área, e de forma mais intensa, um discurso que critica a 
aprendizagem apenas pela prática ou que se aprende apenas por estar efetivamente desenvolvendo a atividade. Basoli (2014) considera o aprender fazendo ou o descobrir aprendendo como um dos mitos relacionados ao aprender Química. Para a autora não se trata apenas de desenvolver as atividades experimentais, mas sim do modo como elas são desenvolvidas e dos objetivos traçados. É importante destacar que pensar a Química como uma área essencialmente experimental e que, por conta disso, "se aprende fazendo" pode produzir uma compreensão de que desenvolver a atividade experimental, por si só, já é suficiente para que ocorra a aprendizagem.

O modelo empirista de ensinar a Química, cuja atividade experimental é considerada a base da produção do conhecimento também é criticado no campo da Educação Química. Para Gonçalves (2009) e Tomazi et al., (2009), um ensino da Química fundamentado essencialmente pela experimentação pode produzir concepções incoerentes sobre o desenvolvimento das Ciências, por exemplo, difundir a ideia de que é apenas por meio das atividades experimentais que os conhecimentos científicos são produzidos. Nesse mesmo viés, outros autores (GALIAZZl; GONÇALVES, 2004; HODSON, 1994) também têm pensado em diferentes propostas de ensino que utilizam como estratégia didática a experimentação, assim como outras metodologias que podem ser utilizadas para potencializar o ensino da Química e que permitem questionar essa concepção de que a experimentação é o único modo de ensinar e aprender efetivamente a Química (GALIAZZI; MORAES, 2002). As discussões destes autores, que criticam e buscam superar esse modo de ver a constituição da Química, reforçam, colocam em movimento e ajudam a evidenciar um discurso que dá à Química um caráter experimental. O próprio movimento de se opor ou tencionar um discurso produz elementos que ajudam a evidenciá-lo.

É importante destacar que compreender a Química como uma área experimental e que por isso "se aprende fazendo", produz efeitos nos cursos de formação de professores, assim como na maneira como esses professores atuarão na Educação Básica. Produz uma compreensão de que a atividade experimental, por si só, já é suficiente para a aprendizagem. Mais do que isso, forma uma compreensão de que 
nunca será uma "química", ou não será "suficientemente químico" o processo que não for experimental. Nesse sentido, cabem questionamentos como: sob essa perspectiva, alguém que trabalhe com a pesquisa aplicada em Química e que se valha de modelos computacionais como, por exemplo, algumas pesquisas em físico-química teórica, comporiam o que se entende ser "química"? Ou, ainda, num curso como o estudado, por meio da análise dos PPCs, nos quais há um conjunto de disciplinas teóricas de uma área para, posteriormente, ser apresentada uma (e somente uma) disciplina experimental dessa mesma área, implicaria em um estudo com "menos química"? Dessas perguntas, vale olharmos para a escola: assumindo que na grande maioria das vezes não há a realização de processos experimentais, em função de uma série de limitações ou desafios presentes no espaço da escola, essa aula de Química não seria suficientemente Química? Ou melhor: pensar, falar, escrever esquematizar conceitos químicos, ainda que num sistema de quadro e giz ou no caderno, não é estar fazendo Química? Problematizações como essas nos levam a perceber a limitação que pode ser a redução de todos os aspectos de uma área como a Química à questão da experimentação. Isso porque tais limitações e reduções que se produzem não param em determinado ponto final, mas se reforçam e atualizam em um processo de produção das compreensões sobre essa área e seus sujeitos. Por exemplo, esse modo de pensar forma posições subjetivas em um discurso, nas quais se inserem os alunos da graduação. O sujeito professor que é constituído nesse campo discursivo irá pensar e desenvolver, quando possível, suas aulas experimentais na Educação Básica, ou mesmo no Ensino Superior, centrada na realização do experimento, desconsiderando outros elementos tidos pelo campo da Educação Química como fundamentais para o ensino e para a aprendizagem, ou negando outros aspectos da própria produção do conhecimento químico. Como os sujeitos estão imersos nesse campo discursivo, provavelmente irão reproduzir o modo de pensar e trabalhar com a Química que se apresenta no Ensino Superior, assim como as práticas postas em ação e que se alinham a esse discurso de uma Química reificada, científica e que são naturalizadas quando se pensa a área. 
A dispersão desses discursos se estende às mídias. Tomazi et al. (2009) e Mesquita e Soares (2008) desenvolveram pesquisas cujo objetivo era identificar como a Química é representada nas mídias, principalmente na televisava, e evidenciaram que, geralmente, ela está associada a laboratórios, a atividades experimentais e à utilização de um método científico. O que se percebe é a reprodução de um modo de compreender a Química, de onde ela ocorre e por quais meios ela é desenvolvida, ressaltando a Química como uma ciência essencialmente experimental.

Embora, na área da Educação Química, haja uma tendência em se colocar em ação um discurso que critique alguns elementos que dão à Química um caráter experimental, como, por exemplo, um modelo de ensino empirista, nela também há a compreensão de que a aprendizagem do conhecimento químico se organiza por meio da investigação de fenômenos naturais, que nada mais é que um modo de abordar a experimentação. A utilização de experimentos que abordem ou que estejam diretamente relacionados ao cotidiano do aluno são temas de diversos trabalhos no campo da Educação Química (KRAISIG; BRAIBANTE, 2017; SILVA et al., 2012; SARTORI et al., 2013). Nesse caso, o que se deseja é a realização de experimentos que estejam muitos mais próximos à realidade dos alunos em detrimento aos que remetem à utilização de laboratórios sofisticados e ao uso de reagentes que os alunos não têm contato.

Os elementos destacados nos permitem visualizar campos que se distinguem no modo de pensar e desenvolver a Química. Um campo que sistematicamente fala de uma ciência reificada, que aborda conhecimentos específicos produzidos em laboratórios equipados e outro que traz uma proposta (não necessariamente realizada diretamente na cotidianidade, mas que se destaca por marcar um outro espaço) que a todo o tempo remete a uma simplificação, à elaboração de experimentos que utilizem materiais mais próximos ao cotidiano dos alunos e que possam, a partir deles, propor problemas reais, se distanciando de uma abordagem que envolva apenas o conhecimento reificado. 
Cada um desses espaços produz modos de se pensar na aprendizagem e no ensino de forma distinta, mas marcam uma experimentação imanente à Química. Também colocam em tensionamento o discurso que circula no curso de formação de professores com o discurso que apresenta um desejo de uma determinada prática docente, essencialmente para a Educação Básica. Os professores, em sua constituição profissional (subjetiva), têm desenvolvido na Educação Básica modos de trabalho que costumeiramente, se tratando do processo experimental, replicam modos muito próprios da Educação Superior - ainda que haja toda uma produção a respeito das limitações dessa proposta sendo discutida no campo da Educação e da Educação Química. Isso está presente porque, mesmo que essas áreas digam que há outros elementos "fundamentais à aprendizagem", no Ensino Superior, mais especificamente nas disciplinas experimentais, se evidencia uma falta dessa preocupação, pois, neste espaço, o objeto não é o ensino ou o sujeito, mas o conhecimento químico, o conhecimento reificado. Por outro lado, no espaço da Escola Básica, atualmente está muito mais presente a formação dos sujeitos escolares como objetivo. Essa diferença de fase encontrada entre um espaço e outro permite, no processo de formação docente, a produção de um sujeito docente que, por também se constituir na conjuntura de um discurso do Ensino Superior de Química que tem por mote o conhecimento, tenderá a reproduzi-lo no espaço da escola - e os efeitos disso são dissonâncias entre as objetivações e as proposições de cada um desses diferentes espaços.

Nesse sentido, a partir de um discurso que delimita uma experimentação que não é problematizada, que tem como função mostrar aos alunos a Química acontecendo e apresentar conceitos reificados, surge elementos que permitem evidenciar uma tendência nas propostas de desenvolvimento de atividades experimentais: a comprovação de teorias. 


\section{AS ATIVIDADES EXPERIMENTAIS COM OBJETIVO DE COMPROVAR TEORIAS}

A ideia de uma Química reificada, que busca dar sentido, tornar concreto os conceitos abstratos por meio da experimentação e que ignora outros aspectos da constituição desse próprio campo, também produz ações e práticas que nos ajudam a evidenciar um discurso que tem nas atividades experimentais uma ferramenta para comprovar as teorias. Esse modo de pensar sobre a Química e a experimentação é visível ou visibilizável (DELEUZE, 2005) nas falas dos professores entrevistados e nos documentos analisados. Uma das formas de mapear o discurso sobre a experimentação é analisar como ele é posto em prática, ou seja, como as propostas de atividades experimentais são desenvolvidas. Nesse sentido, buscamos nas falas dos professores elementos que nos permitissem compreender e evidenciar alguns desses elementos.

Uma dessas práticas é a utilização de apostilas com roteiros estruturados para orientar a ação dos alunos durante as atividades desenvolvidas. Dos professores entrevistados, todos disseram utilizar apostilas com roteiros estruturados dos experimentos a serem desenvolvidos durante a disciplina. Um dos motivos para a utilização de roteiros é a compreensão, por parte dos professores, de que os alunos precisam ter algo para se orientarem.

A análise química envolve várias etapas, então se ele não souber qual etapa, ele pode cometer erros né. É extremamente importante ter um material de apoio, que é esse material físico ai, esse roteiro, então ele tem que ter (P5).

É muito difícil a gente dar uma aula que não seja baseada só nos guias. Por quê? Pra eles iniciarem né, você sempre tem que partir de alguma coisa, porque na verdade uma metodologia de uma prática, nada mais é do que uma receita de bolo né (P3).

Comparar os procedimentos experimentais a uma receita de bolo significa que o aluno apenas vai reproduzir uma sequência de procedimentos já estabelecidos e que, quando seguidos corretamente, obterá um resultado que já é esperado, ou seja, se o 
resultado obtido for efetivamente o que esperado significa que a teoria está certa, foi comprovada. Se o resultado não for o esperado, o experimento precisa ser refeito, como aponta o professor P1:

"Eu gosto de ver se eles tiveram o resultado esperado também. Como são cinco grupos, 15 alunos no máximo, eu consigo acompanhar os resultados esperados também para a prática, e, se não deu o resultado esperado, eles repetem".

O experimento assume a função, não menos importante no discurso, de repetir sistematicamente procedimentos e comprovar teorias e conceitos propostos por cientistas. É importante frisar que a utilização de roteiros definidos não significa garantia de uma prática que visa a comprovação da teoria, pois, é possível utilizar roteiros que auxiliam na problematização dos conceitos (SUART; MARCONDES, 2009).

Quando os professores foram questionados sobre a produção do material que é utilizado nas aulas, os roteiros emergiram como ponto central, e a maioria afirmou utilizar sempre os mesmos, até mesmo para cursos diferentes. $O$ argumento para essa prática envolve basicamente a ideia de que os experimentos utilizados já são consolidados e, dessa forma, compreende-se que são suficientes para trabalhar os conteúdos, como indica a fala do professor P5:

“[...] então a gente já não desenvolve, vamos dizer assim, procedimentos, como são procedimentos que já foram estabelecidos, já são consolidados e consagrados na análise química né".

Esse modo de olhar para os experimentos, como algo que não precisa de modificações ou substituições faz com que eles não sejam problematizados. Não se questiona porque são utilizados esses experimentos e não outros, ou em que eles contribuem na formação e na atuação futura de professores de Química. Não se questiona a utilização de roteiros para o desenvolvimento de atividades experimentais ou não se propõem discussões sobre estes, e isso implica em um efeito notável na constituição da noção experimental na Química. 
A compreensão de que a experimentação tem a função de comprovar a teoria também é visualizada, de forma clara, nos seguintes trechos das falas dos professores entrevistados:

O laboratório, ele é de suma importância né, porque principalmente na química é onde você vai ter o contato ali com a parte de vidraria, vai ver na prática o que está acontecendo. Então é uma maneira, eu acho bem lúdica e clara, de mostrar um pouco da teoria ali para os alunos (P2).

Porque que quando você reage A com B você pode ter um produto final. Você tem aquilo na teoria, você sabe que aquilo existe, mas na prática você não sabe. [...] É você saber a fundamentação das coisas, então o objetivo do laboratório é você colocar em prática aquilo que você viu na teoria né (P3).

A gente tá tentando ver se esse aluno está tendo essa percepção, de ver se o que a gente observa no laboratório realmente bate com o que a gente ensina na teoria. [...] O laboratório, ele é fundamental. Ele te dá subsídio pra gente entender a teoria. Então, ele te mostra para os alunos a importância da química de modo geral no cotidiano. Ele vê a química acontecendo né (P5).

Eu sempre tenho por princípio fazer, dar uma teoria e comprovar ou experimentar aquela teoria com os recursos mais simples que eu tiver e fazer essa comprovação na prática (P6).

Eu acho que não, porque todo aluno de graduação é necessário ter esse convívio, eu acho assim que o laboratório muito importante para tu colocar em prática o que tu viu na teoria né (P8).

Nestes trechos das entrevistas se destaca um discurso que tem nos experimentos a possibilidade de comprovar os conteúdos teóricos. Além disso, reforça a compreensão do laboratório e dos experimentos como local e momento em que o aluno vai ver e vai compreender a Química, do aprender fazendo, pois, por mais que seja trabalhada a parte teórica, é a experimentação que faz o aluno aprender de fato os conteúdos químicos. O experimento que é tido como necessário na produção do conhecimento químico, também o é para a aprendizagem. O entendimento de que a visualização do fenômeno contribui pra a aprendizagem também circula no campo da Educação Química, embora numa compreensão diferenciada, quando articulada aos três níveis de compreensão da Química (MORTIMER; MACHADO; ROMANELLI, 2000; 
JOHNSTONE, 1982). A visualização do fenômeno em seu nível macro é fundamental para que o aluno possa dar sentido aos conceitos abstratos e a suas representações.

Esse discurso de que a experimentação tem por função a comprovação da teoria também é posto em ação e se materializa em documentos oficiais. Por exemplo, no modo como a matriz curricular do curso de formação de professores em Química é organizada. Comumente está ordenada de modo que as disciplinas experimentais são sempre ministras após o aluno já ter trabalhado os conceitos teóricos da disciplina, como no caso do curso integra esta pesquisa (UFPEL, 2016, 2013, 2009). Esta organização contribui e sustenta um discurso no qual os experimentos têm por tarefa a comprovação dos conceitos trabalhados nas aulas teóricas.

Essa percepção se estende à Educação Básica. Ao desenvolverem pesquisa junto a professores de Química da Educação Básica, Silva et al. (2012) observaram que há uma tendência dos professores em utilizar um guia para os alunos desenvolverem as atividades experimentais. Os professores entendem que é necessário o aluno ter um exemplo, ter um modelo para se orientar durante as atividades. Não é diferente nos livros didáticos para a Educação Básica. Vogt, Cecatto e Cunha (2018), ao analisarem imagens e textos presentes em atividades experimentais em diferentes coleções livros didáticos, observam que há uma tendência em se apresentar os experimentos em roteiros fechados, com cada etapa do processo com uma sequência bem definida com os procedimentos que o aluno deve realizar. Os autores ainda destacam que as atividades estão dispostas no final de cada seção, o que, para eles, caracteriza atividades de comprovação da teoria. É importante destacar que, muitas vezes, esse discurso não está necessariamente escrito ou falado, mas está visibilizável no modo como as atividades experimentais são propostas, como e quando elas são desenvolvidas, ou seja, está na ação, na prática e nos materiais produzidos.

Já no campo da Educação Química, esse modo de trabalhar com a experimentação no ensino de Química tem sido muito problematizado. Gonçalves e Marques (2016), por exemplo, criticam o uso de roteiros e colocam essa prática como uma situação limite do Ensino de Química, sendo que, mesmo que os professores 
universitários e alunos da licenciatura não acreditem que essa forma de ensino contribua para a aprendizagem, continuam utilizando-a. Para os autores, esse elemento está presente tanto na Universidade, no modo como as aulas experimentais são desenvolvidas, quanto na Educação Básica, pois a maneira como as atividades experimentais são desenvolvidas na Escola são efeitos daquilo que os professores veem durante a graduação. Nesse posicionamento dos autores se evidencia a ação do discurso no sentido da subjetivação do sujeito. Os professores da Educação Básica fizeram sua graduação em um campo discursivo que prevalece um discurso que põe em prática a realização de experimentos com base em roteiros estruturados e que não se percebe ou não se problematiza as limitações desse modelo na aprendizagem da Química, mas, ainda assim, a reproduzem.

Do mesmo modo como a utilização de roteiros, na área da Educação Química também há um discurso que critica a realização de atividades experimentais com viés de comprovação da teoria. Gonçalves (2009, p. 119) diz que:

[...] crer que um experimento didático seja capaz de comprovar ou refutar uma teoria construída em outro contexto de validação, com outros sujeitos dominadores de métodos e fundamentos sofisticados, é um indício de uma análise pouco congruente com a construção do conhecimento científico e a sua apropriação no âmbito escolar, o que inclui a educação superior.

Para o autor, não faz sentido a realização do experimento nas aulas de Química, na Educação Básica ou no Ensino Superior, para comprovar uma teoria, pois, os experimentos que deram origem àquele conhecimento químico foram desenvolvidos em outras condições, com outros sujeitos e embasados por outros conceitos mais elaborados.

Silva, Uhmann e Heckler (2017, p.191), por exemplo, dizem que "práticas reprodutivas com caráter comprobatório são pobres para alcançar a relação desejada entre teoria e o mundo concreto do estudante". Nesse sentido, este discurso produz tensionamentos em relação àquele que propõe uma Química do cotidiano. Embora haja uma preocupação, principalmente na Educação Básica, em relacionar a Química 
com o cotidiano, desenvolver os experimentos apenas para comprovar uma teoria não contribui para esse propósito, mas, ao contrário, reforça um discurso de uma Química científica, distante do cotidiano dos alunos. Na Educação Básica se deseja a realização de uma Química experimental, mas muito mais próxima da busca por compreender um fenômeno do que propriamente de um experimento com objetivo de reificar um conhecimento. Parte-se de um fenômeno para compreender, sistematizar e organizar os conceitos (MORTIMER; MACHADO; ROMANELLI, 2000; JOHNSTONE, 1982). Todos são modos de compreender a Química, de compreender os processos de produção do conhecimento, de ensino e de aprendizagem, que coexistem em um mesmo campo discursivo e que, num jogo de relações e lutas, produz efeitos efetivos nos modos como a experimentação é trabalhada nas aulas de Química.

Outro ponto que é criticado no campo da Educação Química é a realização de atividades experimentais com o objetivo de desenvolver habilidades técnicas nos alunos. Para Gauche et al. (2008), deve-se evitar, nos cursos de licenciatura em Química, que atividades experimentais tenham por objetivos ensinar atividades específicas do químico, como técnicas, nomes para equipamentos e método científico. Segundo Soares et al. (2012), os licenciandos, que irão atuar no ensino de Química na Educação Básica, não precisam ter uma formação com enfoque na racionalidade técnica, embora ela seja importante, pois os professores precisam de outros fundamentos para atuar na Escola, por exemplo, aprender a articular os conhecimentos específicos da Química com os conhecimentos pedagógicos de forma que a maneira como irá trabalhar os conteúdos químicos contribua para a aprendizagem. Em relação aos objetivos da experimentação na Educação Básica, Gonçalves (2009, p.75) diz:

Para um químico, bacharel ou professor, é imprescindível a apropriação de técnicas relacionadas ao laboratório, se for escopo do processo educacional ao qual ele está submetido a formação de profissionais qualificados no uso de suas atribuições. Isso não significa que alunos da educação básica precisem, igualmente, aprender tais técnicas.

Embora os autores citem a importância da apropriação de técnicas relacionadas ao laboratório para o professor, eles também afirmam que na Educação Básica não há 
necessidade em ter esses conhecimentos como foco. Nesse sentido, se no curso de formação de professores as aulas experimentais forem desenvolvidas de modo que se sobressaia às habilidades técnicas frente a outros conhecimentos, a tendência, pela subjetivação do sujeito, é que esse modelo seja reproduzido nas aulas da Educação Básica.

Na Educação Química também se evidencia um discurso que propõe metodologias diferenciadas nas quais um dos objetivos é a superação desse modelo de experimentação que põe o aluno a atuar passivamente, submetendo-se apenas em reproduzir experimentos com intuito de obter um resultado específico condizente com a literatura. Gonçalves (2009), por exemplo, propõe discussões acerca da utilização de questionamento durante 0 desenvolvimento das atividades que busquem problematizar os conteúdos abordados. Dessa forma, ele acredita que a indagação durante o experimento descaracteriza o desenvolvimento de uma atividade como uma receita de bolo, que o aluno deve seguir exatamente o que é determinado no roteiro.

Gonçalves e Marques (2016) argumentam que as atividades experimentais podem assumir a posição de conteúdo de ensino e promotora de alternativas metodológicas para melhorar a aprendizagem. Dessa forma, a experimentação deixaria de ter como função apenas a comprovação da teoria e passaria a ser um conteúdo a ser trabalhado, discutido e aprendido no curso de formação de professores para modificar os modos como ela é desenvolvida na Educação Básica. Nesse sentido, os experimentos seriam utilizados como uma maneira de ensinar a respeito da experimentação (GONÇALVES, 2009).

Assinalar os distintos modos de produzir a experimentação e mostrar os focos de um processo e outro, mesmo que por uma via da crítica, não implica em assumir o "acerto" ou o "erro" de determinada prática, ou sua característica de melhor ou pior para a aprendizagem, pois há diferentes maneiras de trabalhar com a experimentação no ensino (GALIAZZI e GONÇALVES, 2004; GONÇALVES e MARQUES, 2016), sendo possível evidenciar aspectos propositivos e problemáticos em cada uma delas (BASOLI, 2014). Com essa perspectiva analítica, tais elementos, ao serem descritos e localizados 
enquanto articulados num processo de formação docente e de posterior ação docente nos permite tencioná-los ao discurso que se evidencia no campo da Educação Química e os efeitos que este tensionamento produz nas práticas postas em ação na Educação Básica.

\section{CONCLUSÕES}

O que se evidenciou nesta pesquisa foi a presença de um discurso que produz e reproduz práticas que dão à área da Química um caráter essencialmente experimental e que, ao reforçá-lo, ignoram outros aspectos que integram e constituem os elementos dessa área. No Ensino Superior, especificamente no curso de formação de professores analisado, o que se vê são encaminhamentos que indicam a necessidade de disciplinas experimentais para formar um professor de Química e a importância dos experimentos para comprovar e reificar os conteúdos teóricos que colocam a experimentação não apenas como necessária, mas basal na construção dos conhecimentos químicos. Esse modo de compreender a relação entre a experimentação e a Química também está presente no campo da Educação Química e o que se deseja para a Educação Básica. Isso se evidenciou em elementos como a destacada importância que se dá à utilização de fenômenos do cotidiano para trabalhar os conceitos químicos e os modos como são pensadas as atividades experimentais, muitas vezes como centrais no processo de ensino e de aprendizagem.

É nessas configurações distintas das propostas que surge um tensionamento no campo da formação de professores. O sujeito professor é constituído e subjetivado num espaço em que se propaga um modo de pensar e desenvolver a experimentação distinto das características e possibilidades daquele em que irá trabalhar. Se o professor, ao longo de sua graduação, trabalha a experimentação apenas utilizando roteiros estruturados e com objetivo de comprovar a teoria, ele reproduzirá o modo de ensinar que se habituou, que se 
familiarizou e que acabou naturalizando. Se estiver naturalizada a ideia de que o experimento deva ocorrer apenas no laboratório, no caso da Escola não possuir laboratório ou não oferecer condições para uma aula no laboratório, o professor não o desenvolverá. Se ele entender que o experimento é utilizado para comprovar e reificar uma teoria, essa será a função da experimentação em suas aulas, assim como é concebível assumir que apenas desenvolver um experimento já é o suficiente para aprender os conceitos envolvidos na atividade. Entretanto, ao não realizar tais elementos experimentais, como se colocaria sua aula? Menos química? E o que implicaria isso? Esses são alguns dos efeitos que foi possível mapear e descrever por meio da análise do corpus da pesquisa.

Acreditamos que os apontamentos feitos neste trabalho são importantes para pensarmos e repensarmos as práticas docentes desenvolvidas nos cursos de formação de professores de Química e na própria ação na Escola Básica. Todavia, ao determos maior atenção no Ensino Superior, é possível evidenciar que esse nível de ensino tem função essencial na possível promoção de mudanças na Educação Básica, haja visto seu carácter constitutivo da ação de um discurso. Portanto, é fundamental que a formação discursiva na qual docentes em formação para a Escola Básica estejam inseridos seja coerente e busque ser articulada com aquilo que se deseja deles em seu campo profissional de ação, a escola, e descrever os tensionamentos, as críticas e as assumpções neste trabalho pode colaborar para tal coerência.

\section{REFERÊNCIAS}

ATKINS, P.; JONES, L. Princípios de Química: questionando a vida moderna e o meio ambiente. Porto Alegre: Bookman, 2012.

BASOLI, F. Atividades práticas e o ensino-aprendizagem de ciência(s): mitos, tendências e distorções. Ciência e Educação, v.20, n. 3, p. 579-593, 2014.

DELEUZE, G. Foucault. São Paulo: Brasiliense, 2005. 
FOUCAULT, M. A Arqueologia do Saber. 8. ed. Rio de Janeiro: Forense Universitária, 2016.

A Ordem do Discurso. São Paulo: Edições Loyola, 2014.

GALIAZZI, M. D. C.; GONÇALVES, F. P. A natureza pedagógica da experimentação: uma pesquisa na licenciatura em química. Química Nova, v.27, n. 2, p. 326-331, 2004.

GALIAZZI, M. D. C.; MORAES, R. Educação pela pesquisa como modo, tempo e espaço de qualificação da formação de professores de Ciências. Ciência e Educação, v.8, n.2, p. 237-252, 2002.

GAUCHE, R. et al. Formação de professores de química: concepções e proposições. Química Nova na Escola, n.27, p. 26-29, 2008.

GIORDAN, M. O papel da experimentação no ensino de química. Química Nova na Escola, n.10, p. 43-49, 1999.

GONÇALVES, F. P. A problematização das atividades experimentais no desenvolvimento profissional e na docência dos formadores de professores de Química. 2009. 234 f. Tese (Doutorado em Educação Científica e Tecnológica), Universidade Federal de Santa Catarina, Porto Alegre, Brasil, 2009.

GONÇALVES, F. P.; MARQUES, C. A. A Experimentação na Docência de Formadores da Área de Ensino de Química. Química Nova na Escola, v.38, n.1, p. 84-98, 2016.

HODSON, D. Hacia un enfoque más crítico del trabajo de laboratorio. Enseñanza de Las Ciências, v.12, n.3, p. 299-313, 1994.

JOHNSTONE, A. Macro and microchemistry. The School Science Review, p. 377-379, 1982.

KRAISIG, A. R.; BRAIBANTE, M. E. F. A Química das Cores: uma oficina temática para o ensino e aprendizagem de Química. Ciência e Natura, v.39, n.3, p. 687-700, 2017.

LATUR, B.; WOOLGAR, S. A vida de laboratório: a produção dos fatos científicos. Rio de Janeiro: Relume Dumará, 1997.

LENOIR, T. Instituindo a Ciência: A produção cultural das disciplinas científicas. São Leopoldo: Unisinos, 2004.

MARÍN-DÍAZ, D. L. Infância: discussões contemporâneas, saber pedagógico e governamentalidade. 2009. 199f . Dissertação (Mestrado em Educação), Universidade Federal do Rio Grande do Sul, Porto Alegre, 2009.

MESQUITA, N. A. D. S.; SOARES, M. H. F. B. Visões de Ciências em desenhos animados: uma alternativa para o debate sobre a construção do conhecimento científico em sala de aula. Ciência e Educação, v.14, n.3, p. 417-429, 2008. 
MORI, R. C.; CURVELO, A. A. D. S. A polissemia da palavra "Experimentação" e a Educação em Ciências. Química Nova na Escola, v.39, n.3, p. 291-304, 2017.

MORTIMER, E. F.; MACHADO, A. H.; ROMANELLI, L. I. A proposta curricular no ensino de Química do Estado de Minas Gerais: fundamentos e pressupostos. Química Nova, v.23, n.2, p. 273-283, 2000.

PASTORIZA, B. S.; DEL PINO, J. C. A Educação Química em discurso: uma análise a partir da revista Química Nova na Escola (1995-2014). Química Nova na Escola, v.39, n.2, p. 204-219, 2017.

QUADROS, A. L. D.; et al. Ensinar e aprender Química: a percepção dos professores do Ensino Médio. Educar em Revista, n.40, p. 159-176, 2011.

SARTORI, E. R.; et al. Construção de Uma Célula Eletrolítica para o Ensino de Eletrólise a Partir de Materiais de Baixo Custo. Química Nova na Escola, v.35, n.2, p. 107-111, 2013.

SILVA, A. C. A. D.; UHMANN, R. I. M.; HECKLER, V. A experimentação e o ensino de química. In: PASTORIZA, B. D. S.; SANGIOGO, F. A.; BOSENBECKER, V. K. Reflexões e debates em Educação Química. Curitiba: CRV, 2017. p. 262.

SILVA, J. A. D. et al. Concepções e práticas de experimentação nos anos iniciais do ensino fundamental. Linhas Críticas, v.18, n.25, p. 127-150, 2012.

SOARES, M. H. F. B. et al. A formação de professores de química pela pesquisa: algumas ações da área de ensino de química do Instituto de Química da Universidade Federal de Goiás. Espaço Plural, n.26, p. 70-87, 2012.

SUART, R. C.; MARCONDES, M. E. R. A manifestação de habilidades cognitivas em atividades experimentais investigativas no ensino médio de química. Ciência e Cognição, v.14, n.1, p. 50 74, 2009.

TOMAZI, A. L. et al. O que é e quem faz ciência? Imagens sobre a atividade científica divulgadas em filmes de animação infantil. Ensaio, v.11, n.2, 2009.

VOGT, C. F. G.; CECATTO, A. J.; CUNHA, M. B. D. A fotografia científica e as atividades experimentais: livros didáticos de química. Actio, v.3, n.1, p. 56-74, 2018.

UNIVERSIDADE FEDERAL DE PELOTAS (UFPel). Projeto Pedagógico. 2016. Disponível em http://bit.ly/31LYEhK. Acesso em 18 jul 2018.

Projeto Pedagógico. 2013. Disponível em http://bit.ly/31Pq4DB. Acesso em 18 jul. 2018.

Projeto Pedagógico. 2009. Disponível em http://bit.ly/3bwtGPI. Acesso em 18 jul. 2018. 


\section{Contribuições de autoria}

\section{1 - Edson Frozza}

Doutorando em educação pela Universidade Federal de Pelotas https://orcid.org/0000-0003-4350-1860 - efrozza@outlook.com Contribuição: Autor principal

\section{2 - Bruno dos Santos Pastoriza}

Doutor e mestre em Educação em Ciências Química da Vida e Saúde, Coordenador do Laboratório de Ensino de Química (LABEQ) e orientador de pós-graduação na Universidade Federal de Pelotas https://orcid.org/0000-0002-5824-306X - bspastoriza@gmail.com Contribuição: Segundo autor

\section{Como citar este artigo}

FROZZA, E.; PASTORIZAI, B. S. “A Química é uma área experimental!": discursos sobre a experimentação em um curso. Ciência e Natura, Santa Maria, v. 43, e5, p. 1-26, 2021. DOI 10.5902/2179460X43465. Available at: https://doi.org/10.5902/2179460X43465. 